\title{
STUDI BEBAN PENCEMARAN SUNGAI KAPUAS AKIBAT BUANGAN DARI DRAINASE DI KECAMATAN PONTIANAK UTARA KOTA PONTIANAK \\ (Studi Kasus: Kelurahan Siantan Tengah dan Kelurahan Siantan Hilir)
}

\author{
Nia Febrianti ${ }^{1}$, Johnny MTS' ${ }^{2}$, Rizki Purnaini ${ }^{1}$ \\ ${ }^{1}$ Program Studi Teknik Lingkungan, Universitas Tanjungpura, Pontianak \\ ${ }^{2}$ Program Studi Teknik Sipil, Universitas Tanjungpura, Pontianak \\ Email: febrianti24@gmail.com
}

\begin{abstract}
ABSTRAK
Masyarakat kota Pontianak khususnya di Kecamatan Pontianak Utara sebagian besar menggunakan beberapa anak sungai / parit sebagai aliran pembuangan limbah, sistem pembuangan di Pontianak masih menerapkan on site system dalam arti black water dibuang ke tangki septik (septic tank) sedangkan grey water langsung dibuang ke anak sungai / parit yang menyebabkan air sungai / parit tersebut menjadi tercemar sehingga kualitas air sungai Kapuas menurun. Melihat dari adanya masalah ini maka perlu dilakukan suatu usaha untuk mengetahui seberapa besar kontribusi limbah domestik khususnya Kelurahan Siantan Tengah dan Siantan Hilir Kecamatan Pontianak Utara dalam memberikan beban pencemaran bagi Sungai Kapuas. Pada penelitian ini dilakukan analisis terhadap enam anak sungai/parit yang ada di Kecamatan Pontianak Utara untuk mengetahui akumulasi beban pencemaran yang akan masuk ke Sungai Kapuas serta potensi beban pencemaran untuk 20 tahun kedepan, sehingga dapat dilakukan upaya pengendalian yang tepat terhadap masing masing anak sungai/parit berdasarkan jenis pencemaran dan juga tingkat pencemarannya.

Penelitian ini dilakukan dienam anak sungai / parit yaitu Parit Pekong, Parit Wan Salim, Parit Bangseng, Parit Makmur di Kelurahan Siantan Tengah, serta Sungai Putat dan Sungai Selamat di Kelurahan Siantan Hilir Kecamatan Pontianak Utara, sedangkan perhitungan beban pencemaran hanya dapat dihitung pada lima anak sungai / parit yakni Parit Pekong, Parit Wan Salim, Parit Makmur, Sungai Putat dan Sungai Selamat. Sampel air diambil pada saat kondisi surut tanggal 2 Maret pukul 18.49 WIB dan pada saat kondisi pasang pada tanggal 3 Maret pukul 12.00 WIB. Sampel air diambil secara bersamaan pada enam titik lokasi, kemudian dilakukan pengukuran penampang saluran, kecepatan aliran dan debit dari masing-masing anak sungai/parit. Parameter yang dianalisis adalah BOD, COD, Total Phosfat, Total Nitrogen, Total Coliform, suhu dan $\mathrm{pH}$.

Beban pencemaran (BP) dihitung dengan menggunakan rumus yang terdapat dalam Permen LH Nomor 1 Th 2010. Nilai total BP dari lima anak sungai/parit sebagai berikut: -kondisi surut a) BP BOD $=1.146$ $\mathrm{kg} /$ hari b) BP COD $=10.301 \mathrm{~kg} / \mathrm{hari}$ c) BP Total Phosfat $=394 \mathrm{~kg} /$ hari d) BP Total Nitrogen $=1.387 \mathrm{~kg} / \mathrm{hari}$. kondisi pasang a) BP BOD $=3.563 \mathrm{~kg} / \mathrm{hari}$ b) $B P C O D=21.146 \mathrm{~kg} / \mathrm{hari}$ c) $\mathrm{BP}$ Total Phosfat $=445 \mathrm{~kg} / \mathrm{hari} \mathrm{d}$ ) $\mathrm{BP}$ Total Nitrogen $=1.173 \mathrm{~kg} /$ hari. Potensi beban pencemaran $(\mathrm{PBP})$ dihitung sampai 20 tahun kedepan. PBP yang dihasilkan dari kegiatan domestik yaitu pemukiman yang berada disekitar anak sungai / parit setiap dalam 5 tahun akan naik sebesar $8 \%$. PBP dari setiap parameter untuk 20 tahun kedepan sebagai berikut : BOD akan dihasilkan sebesar $4.612 \mathrm{~kg} / \mathrm{hari}$, COD akan dihasilkan sebesar $8.841 \mathrm{~kg} / \mathrm{hari}$, Total Nitrogen akan dihasilkan sebesar $1.975 \mathrm{~kg} /$ hari dan Total Phosfat akan dihasilkan sebesar $331 \mathrm{~kg} / \mathrm{hari}$. Parit Pekong memiliki presentase paling besar yaitu 34,91\% dalam total PBP yang akan masuk ke Sungai Kapuas. Dari hasil penelitian maka harus dilakukan pengendalian pencemaran air untuk menjamin kualitas air agar sesuai dengan baku mutu air PP No. 82 Th 2001. Upaya pengendalian pencemaran air yang bisa dilakukan Pemerintah Kota Pontianak adalah: a) pembinaan kesadaran masyarakat sejak dini khususnya yang tinggal di sekitar sungai/parit b) Merealisasikan perencanaan pembuatan IPAL di Pontianak c) pada industri yang sudah mempunyai IPAL diharapkan dapat merawat IPAL tersebut sehingga tidak akan menghasilkan limbah yang melampaui baku mutu.
\end{abstract}

Kata - kata kunci : Sungai Kapuas di Pontianak, Beban Pencemaran, Pengendalian Pencemaran 


\begin{abstract}
The community of Pontianak city especially in North Pontianak District, most of people use tributary / drainage as sewage flow, exhaust system in Pontianak were still apply on - site system that black water dumped into septic tank while the grey water directly dumped into the tributary / drainage that cause water to be polluted so that the water quality of the Kapuas River decreased. Viewed from the existence of this problem then it needs to be made an attempt to find out how large the contribution of domestic waste in Kelurahan Siantan Tengah and Kelurahan Siantan Hilir North Pontianak District in delivering a load of pollution for the Kapuas River. In this research was conducted an analysis of the six tributaries / drainage in North Pontianak District to find out the accumulated of pollution load that will flow to Kapuas River and the potential of pollution load for 20 years, so it can be control to each tributary / drainage based on the type and level contamination.

This research is done in six tributaries / drainage were Parit Pekong, Parit Wan salim, Parit Bangseng, Parit Makmur in Kelurahan Siantan Tengah, Sungai Putat and Sungai Selamat in Kelurahan Siantan Hilir, North Pontianak District while the calculation of pollution load can only be calculated at five tributaries / drainage there were Parit Pekong, Parit Wan Salim, Parit Makmur, Sungai Putat and Sungai Selamat. Water samples taken at the time of low tide condition on 2 March 2014 at $06.49 \mathrm{pm}$ and high tide condition on 3 March 2014 at 12.00 pm. Water samples taken simultaneously at six point location and then measurements of the channel dimension (width and depth), flow velocity and water discharge from each tributaries/drainage. The parameters are BOD, COD, Phosfat Total, Nitrogen Total, Coliform Total, pH, and temperature.

Pollution load (PL) calculated with formula from Regulation of The Minister of The Environment No. 1 of 2010. The results of $P L$ from five tributaries / drainage are : -low tide condition a) $P L B O D=1.146 \mathrm{~kg} /$ day b) $P L C O D=10.301 \mathrm{~kg} /$ day c) $P L$ Phosfat Total $=394 \mathrm{~kg} /$ day d) $P L$ Nitrogen Total $=1.387 \mathrm{~kg} /$ day. -high tide condition a) $P L B O D=3.563 \mathrm{~kg} /$ day b) $P L C O D=21.146 \mathrm{~kg} /$ day c) $P L$ Phosfat Total $=445 \mathrm{~kg} /$ day d) $P L$ Nitrogen Total $=1.173 \mathrm{~kg} /$ day. Potential of Pollution Load $(P P L)$ calculated until 20 years later. The result of $P P L$ from domestic activities that are human settlement around the tributary / drainage every 5 years will increase by $8 \%$. PPL of each parameters for 20 years later are: BOD will be produced by $4.612 \mathrm{~kg} /$ day, COD will be produced by $8.841 \mathrm{~kg} /$ day, Nitrogen Total will be produced by $1.975 \mathrm{~kg} /$ day and Phosfat Total will be produced by $331 \mathrm{~kg} /$ day. Parit Pekong has the higher percentage is $34,91 \%$ in total PPL that will go into Kapuas River. From the result of research should be do control of water pollution to make sure that water quality can match with quality of water according Government Regulation No. 82 of 2001. The control effort of water pollution that can be do by The Government of Pontianak City are : a) fostering public awareness from early age especially those living around tributary / river b) realization of planning the manufacture of IPAL (off - site system) in Pontianak c) on industry that already has IPAL is expected to keep and take care of the IPAL so industry will not produce the waste that exceeds the quality standard.
\end{abstract}

Keywords: Kapuas River in Pontianak, Pollution Load, Pollution Control 


\section{Pendahuluan}

Masyarakat kota Pontianak khususnya di Kecamatan Pontianak Utara sebagian besar menggunakan beberapa anak sungai / parit sebagai aliran pembuangan limbah, dimana di Pontianak masih menerapkan on site system dalam arti black water yang langsung dibuang ke tangki septik (septic tank) sedangkan grey water langsung dibuang ke anak sungai / parit yang menyebabkan air sungai / parit tersebut menjadi tercemar sehingga kualitas air Sungai Kapuas menurun. Melihat dari adanya masalah ini maka perlu dilakukan suatu usaha untuk mengetahui seberapa besar kontribusi masyarakat Kota Pontianak khususnya Kelurahan Siantan Tengah dan Siantan Hilir Kecamatan Pontianak Utara dalam memberikan beban pencemaran bagi Sungai Kapuas yang ditinjau dari akumulasi beban pencemaran yang akan masuk ke badan air Sungai Kapuas.

Penelitian ini dilakukan di Kecamatan Pontianak Utara. Kecamatan Pontianak Utara mempunyai luas wilayah $37,22 \mathrm{~km}^{2}$ dan jumlah penduduk 114.828 jiwa, angka laju pertumbuhan penduduk Kecamatan Pontianak Utara untuk tahun 2000-2010 adalah sebesar 1,7 \% (BPS, 2012). Pada Kecamatan Pontianak Utara ini terdapat empat kelurahan diantaranya yaitu Kelurahan Siantan Hulu, Kelurahan Siantan Tengah, Kelurahan Siantan Hilir dan Kelurahan Batu Layang. Penelitian ini akan dilakukan pada 4 anak sungai / parit yang terletak di Kelurahan Siantan Tengah yaitu Parit Pekong, Parit Wan Salim, Parit Bangseng dan Parit Makmur, dan 2 anak sungai / parit terletak pada Kelurahan Siantan Hilir yakni Sungai Putat dan Sungai Selamat.

\section{Metodologi Penelitian}

Penelitian ini dilakukan pada anak sungai/parit yang ada di Kelurahan Siantan Tengah yaitu Parit Pekong, Parit Wan Salim, Parit Bangseng, Parit Makmur dan di Kelurahan Siantan Hilir yaitu Sungai Putat dan Sungai Selamat. Pengambilan sampel dilakukan pada kondisi surut tanggal 2 Maret 2014 pukul 18.49 WIB dan pada kondisi pasang tanggal 3 Maret 2014 pukul 12.00 WIB, dengan tahap penelitian sebagai berikut :

a. Tahap persiapan yaitu berupa pengumpulan referensi dari berbagai literatur yang meliputi jurnal, skripsi dan buku yang berkenaan dengan kualitas air dan beban pencemaran.

b. Tahap pengumpulan data berupa data primer dan data sekunder. Data primer yang dikumpulkan berupa data kondisi eksisting dimensi anak sungai/parit, kecepatan aliran, debit serta data kualitas air dari hasil pengujian laboratorium. Data sekunder yang dikumpulkan berupa peta kecamatan Pontianak Utara yang didapat dari BPS Kota Pontianak, monografi Kelurahan Siantan Tengah dan Siantan Hilir dari saing-masing kantor kelurahan.

c. Tahap penelitian yaitu menentukan lokasi pengambilan sampel air (titik sampling), mengukur luas penampang (lebar dan kedalaman) dari ke enam anak sungai/parit, mengukur dan menghitung kecepatan aliran, menghitung debit aliran, dan mengambil sampel kualitas air.

d. Analisa kualitas air dari ke enam anak sungai / parit. Proses analisa kualitas air yaitu dengan membandingan data hasil uji kualitas air dengan baku mutu PP No. 82 Tahun 2001 tentang Pengelolaan Kualitas Air dan Pengendalian Pencemaran Air, menghitung beban pencemaran dari lima anak sungai / parit diantaranya Parit Pekong, Parit Wan Salim, Parit Makmur, Parit Wan Salim, Sungai Putat dan Sungai Selamat, serta mengitung estimasi potensi beban pencemaran domestik untuk 20 tahun kedepan sampai tahun 2034. Perhitungan beban pencemaran dan estimasi potensi beban pencemaran domestik menggunakan rumus dari PerMen LH No. 1 Tahun 2010. Beban pencemaran dihitung menggunakan rumus :

$B P S=(C s)_{j} \times Q s \times f$

Keterangan:

BPS = Beban Pencemaran Sungai $(\mathrm{kg} /$ hari)

(Cs) $\quad=$ Kadar terukur sebenarnya unsur pencemar $(\mathrm{mg} /$ liter $)$

Qs = Debit air sungai $\left(\mathrm{m}^{3} /\right.$ hari) 
$\mathrm{f} \quad=$ faktor konfersi $=\frac{1 \mathrm{~kg}}{1.000 .000 \mathrm{mg}} \times \frac{1000 \text { liter }}{1 \mathrm{~m}^{3}}=0,001$

Dan Estimasi potensi beban pencemaran dihitung menggunakan rumus :

$P B P D=$ Luas $\times$ kepadatan penduduk $\times$ faktor emisi

dalam Keterangan :

PBPD

= Potensi beban pencemaran domestik

Kepadatan penduduk

= kepadatan penduduk pada wilayah tersebut

Faktor emisi

$=($ dapat dilihat tabel faktor emisi limbah domestik tabel 1$)$

Tabel 1. Emisi Air Limbah Domestik

\begin{tabular}{|c|c|c|c|c|}
\hline Sumber Pencemar Air & \multicolumn{4}{|c|}{ Faktor Emisi (gr/kapita/hari) } \\
\cline { 2 - 5 } (Pemukiman) & BOD & COD & TN & TP \\
\hline Limbah Cair Tanpa Diolah & 53 & 101,6 & 22,7 & 3,8 \\
Pakai Septic Tank & 12,6 & 24,2 & 5,4 & 0,9 \\
\hline
\end{tabular}

\section{Hasil dan Analisa}

A. Hasil Pengukuran Luas Penampang Basah Saluran

Data yang diperlukan dalam perhitungan yaitu dimensi saluran berupa lebar dan kedalaman yang didapat dari hasil pengukuran di lapangan. Hasil pengukuran dimensi dan perhitungan luas penampang dari keenam anak sungai / parit dapat dilihat pada Tabel 2.

Tabel 2. Luas Penampang Basah Saluran Pada Saat Surut dan Pasang

\begin{tabular}{|l|l|c|c|c|c|c|c|}
\hline \multirow{2}{*}{ No } & \multirow{2}{*}{$\begin{array}{c}\text { Nama } \\
\text { Sungai / Parit }\end{array}$} & \multicolumn{2}{|c|}{ Tinggi Muka Air $(\mathbf{m})$} & \multicolumn{2}{c|}{ Lebar $(\mathbf{m})$} & \multicolumn{2}{c|}{$\mathbf{A}\left(\mathbf{m}^{2}\right)$} \\
\cline { 3 - 7 } & & Surut & Pasang & Surut & Pasang & Surut & Pasang \\
\hline 1 & Parit Pekong & 0,60 & 0,68 & 4,66 & 4,66 & 2,80 & 3,17 \\
2 & Parit Wan Salim & 0,40 & 0,65 & 4,87 & 4,87 & 1,95 & 3,17 \\
3 & Parit Bangseng & - & 0,10 & - & 4,90 & - & 0,49 \\
4 & Parit Makmur & 0,60 & 0,80 & 5,70 & 5,70 & 3,42 & 4,56 \\
5 & Sungai Putat & 0,79 & 0,90 & 11,22 & 11,22 & 8,86 & 10,10 \\
6 & Sungai Selamat & 1,08 & 1,24 & 5,78 & 5,78 & 6,24 & 7,17 \\
\hline
\end{tabular}

Luas penampang Parit Bangseng pada saat kondisi surut tidak dapat dihitung dikarenakan air yang sangat kering sekali pada parit tersebut pada saat pengambilan sampel air.

\section{B. Hasil Pengukuran Kecepatan Aliran}

Pengukuran kecepatan aliran pada anak sungai / parit dilakukan dengan pelampung berupa kayu yang diikat dengan menggunakan tali dan dilakukan secara bersamaan disemua titik lokasi pengambilan sampel air. Pada pengukuran kecepatan aliran dengan pelampung sebelumnya telah dikalibrasi dengan menggunakan alat current meter. Kecepatan aliran setelah dikalibrasi dapat dilihat pada Tabel 3. 
Tabel 3. Data Kecepatan Aliran Kalibrasi Pada Saat Surut dan Pasang

\begin{tabular}{|l|l|c|c|}
\hline \multirow{2}{*}{ No } & \multirow{2}{*}{$\begin{array}{c}\text { Nama } \\
\text { Sungai / Parit }\end{array}$} & \multicolumn{2}{|c|}{ Kecepatan Aliran (m/detik) } \\
\cline { 3 - 4 } & Surut & Pasang \\
\hline 1 & Parit Pekong & 0,0595 & 0,2130 \\
2 & Parit Wan Salim & 0,0864 & 0,1774 \\
3 & Parit Bangseng & - & 0,0239 \\
4 & Parit Makmur & 0,0957 & 0,1203 \\
5 & Sungai Putat & 0,0830 & 0,1655 \\
6 & Sungai Selamat & 0,0750 & 0,1758 \\
\hline
\end{tabular}

Kecepatan aliran rata-rata terbesar pada kondisi pasang terletak pada Sungai Selamat, sedangkan pada Saat kondisi surut terletak pada Parit Makmur. Hal ini dipengaruhi oleh dimensi saluran berupa lebar dan kedalaman dan juga dipengaruhi oleh arus pasang dan surut Sungai Kapuas.

\section{Hasil Perhitungan Debit Aliran}

Hasil perhitungan debit aliran keenam anak sungai / parit dapat dilihat pada Tabel 4.

Tabel 4. Data Perhitungan Debit Aliran Pada Saat Surut dan Pasang

\begin{tabular}{|c|l|c|c|}
\hline \multirow{2}{*}{ No } & \multicolumn{1}{|c|}{ Nama } & \multicolumn{2}{|c|}{$\mathbf{Q}\left(\mathbf{m}^{\mathbf{3}} /\right.$ detik) } \\
\cline { 3 - 4 } & Sungai / Parit & Surut & Pasang \\
\hline 1 & Parit Pekong & 0,166 & 0,675 \\
2 & Parit Wan Salim & 0,168 & 0,562 \\
3 & Parit Bangseng & - & 0,012 \\
4 & Parit Makmur & 0,328 & 0,549 \\
5 & Sungai Putat & 0,736 & 1,671 \\
6 & Sungai Selamat & 0,468 & 1,260 \\
\hline
\end{tabular}

Pada Tabel 4 menunjukkan pada kondisi surut debit yang paling besar terjadi di Sungai Putat sebesar $0,736 \mathrm{~m}^{3} /$ detik dan pada kondisi pasang debit aliran yang paling besar terjadi di Sungai Putat pula sebesar $1,671 \mathrm{~m}^{3} /$ detik. Nilai debit aliran ini dipengaruhi oleh kecepatan aliran dan luas penampang basah pada masing-masing anak sungai / parit.

\section{Data Kualitas Air}

Data kualitas air dari hasil pengujian sampel air pada keenam anak sungai / parit dengan parameter suhu, $\mathrm{pH}, \mathrm{BOD}_{5}, \mathrm{COD}$, Total Fosfat, Total Nitrogen, dan Total Coliform dapat dilihat pada Tabel 5 dan Tabel 6.

Tabel 5. Data Pengujian Kualitas Air pada Kondisi Surut

\begin{tabular}{|l|c|c|c|c|c|c|c|}
\hline \multirow{2}{*}{$\begin{array}{c}\text { Nama } \\
\text { Sungai / Parit }\end{array}$} & $\begin{array}{c}{ }^{*} \text { Suhu } \\
\left({ }^{\circ} \mathbf{C}\right)\end{array}$ & ${ }^{*} \mathbf{p H}$ & $\begin{array}{c}\mathbf{B O D}_{\mathbf{5}} \\
(\mathbf{m g} / \mathbf{l})\end{array}$ & $\begin{array}{c}\text { COD } \\
(\mathbf{m g} / \mathbf{l})\end{array}$ & $\begin{array}{c}\text { Total } \\
\text { Fosfat } \\
(\mathbf{m g} / \mathbf{l})\end{array}$ & $\begin{array}{c}\text { Total } \\
\text { Nitrogen } \\
(\mathbf{m g} / \mathbf{l})\end{array}$ & $\begin{array}{c}\text { Total Coliform } \\
(\mathbf{M P N} / \mathbf{1 0 0 m l})\end{array}$ \\
\hline Parit Pekong & 28 & 7,6 & 6,77 & 49,33 & 0,94 & 10,239 & 4 \\
Parit Wan Salim & 27 & 7,7 & 6,44 & 58,09 & 1,69 & 13,651 & 4 \\
Parit Bangseng & 27 & 8,2 & 33,89 & 81,90 & 5,65 & 40,954 & 4 \\
Parit Makmur & 28 & 6,9 & 6,10 & 54,28 & 2,03 & 5,6880 & 4 \\
Sungai Putat & 28 & 5,9 & 8,64 & 55,04 & 2,07 & 10,239 & 10 \\
Sungai Selamat & 29 & 5,6 & 5,76 & 91,80 & 4,12 & 5,6880 & 17 \\
\hline
\end{tabular}


Tabel 6. Data Pengujian Kualitas Air pada Kondisi Pasang

\begin{tabular}{|l|c|c|c|c|c|c|c|}
\hline \multirow{2}{*}{$\begin{array}{c}\text { Nama } \\
\text { Sungai / Parit }\end{array}$} & $\begin{array}{c}*^{*} \text { Suhu } \\
\left({ }^{\circ} \mathbf{C}\right)\end{array}$ & $*_{\mathbf{p H}}$ & $\begin{array}{c}\mathbf{B O D}_{\mathbf{5}} \\
(\mathbf{m g} / \mathbf{l})\end{array}$ & $\begin{array}{c}\text { COD } \\
(\mathbf{m g} / \mathbf{l})\end{array}$ & $\begin{array}{c}\text { Total } \\
\text { Fosfat } \\
(\mathbf{m g} / \mathbf{l})\end{array}$ & $\begin{array}{c}\text { Total } \\
\text { Nitrogen } \\
(\mathbf{m g} / \mathbf{l})\end{array}$ & $\begin{array}{c}\text { Total Coliform } \\
(\mathbf{M P N} / 100 m \mathbf{l})\end{array}$ \\
\hline Parit Pekong & 30 & 6,3 & 10,84 & 52,00 & 0,59 & 3,413 & 4 \\
Parit Wan Salim & 31 & 6,8 & 20,16 & 56,57 & 0,81 & 3,413 & 4 \\
Parit Bangseng & 30 & 8,3 & 101,69 & 104,76 & 4,91 & 38,679 & 17 \\
Parit Makmur & 31 & 6,4 & 16,10 & 54,66 & 0,79 & 2,275 & 4 \\
Sungai Putat & 34 & 6,5 & 4,40 & 59,61 & 1,07 & 2,275 & 4 \\
Sungai Selamat & 34 & 6,0 & 5,08 & 38,28 & 1,65 & 3,413 & 4 \\
\hline
\end{tabular}

Pengujian kualitas air untuk parameter $\mathrm{BOD}_{5}, \mathrm{COD}$, Total Fosfat, Total Nitrogen dilakukan di Laboratorium Fakultas Pertanian Universitas Tanjungpura sedangkan Total Coliform diuji di Laboratorium Sucofindo Pontianak.

\section{E. Analisa Kualitas Air}

Hasil analisa kualitas air menunjukkan dalam setiap parameter sudah melampaui baku mutu kelas I, II, dan III dari PP No. 82 Tahun 2001.

\section{F. Analisa Perhitungan Beban Pencemaran}

Beban pencemaran sungai adalah jumlah suatu unsur pencemar yang terkandung dalam air sungai. Beban pencemaran juga merupakan besaran satuan berat zat pencemar dalam satuan waktu. Beban pencemaran hanya dihitung pada lima anak sungai / parit yakni Parit Pekong, Parit Wan Salim, Parit Makmur, Sungai Putat dan Sungai Selamat. Parit Bangseng tidak bisa dihitung beban pencemarannya diakibatkan pada saat penelitian dan pengambilan sampel air debit pada parit tersebut tidak dapat diukur karena tidak adanya aliran pada Parit Bangseng.

Tabel 7. Data Perhitungan Beban Pencemaran Sungai pada saat Surut

\begin{tabular}{|l|c|c|c|c|}
\hline \multirow{2}{*}{ Nama Saluran } & \multicolumn{4}{|c|}{ Beban Pencemaran (kg/hari) } \\
\cline { 2 - 5 } & BOD & COD & Total Fosfat & Total Nitrogen \\
\hline Parit Pekong & 97,10 & 707,51 & 13,48 & 146,85 \\
Parit Wan Salim & 93,48 & 843,19 & 24,53 & 198,15 \\
Parit Makmur & 172,87 & $1.538,25$ & 57,53 & 161,19 \\
Sungai Putat & 549,42 & 3.500 & 131,63 & 651,10 \\
Sungai Selamat & 232,91 & $3.711,95$ & 166,59 & 230,0 \\
\hline \multicolumn{1}{|c|}{ Total } & $\mathbf{1 . 1 4 5 , 7 7}$ & $\mathbf{1 0 . 3 0 0 , 9 2}$ & $\mathbf{3 9 3 , 7 7}$ & $\mathbf{1 . 3 8 7 , 2 9}$ \\
\hline \multicolumn{1}{|c|}{ Total } & $\mathbf{1 . 1 4 6}$ & $\mathbf{1 0 . 3 0 1}$ & $\mathbf{3 9 4}$ & $\mathbf{1 . 3 8 7}$ \\
\hline
\end{tabular}

Tabel 8. Data Perhitungan Beban Pencemaran Sungai pada saat Pasang

\begin{tabular}{|l|c|c|c|c|}
\hline \multirow{2}{*}{ Nama Saluran } & \multicolumn{4}{|c|}{ Beban Pencemaran (kg/hari) } \\
\cline { 2 - 5 } & BOD & COD & Total Fosfat & Total Nitrogen \\
\hline Parit Pekong & 632,19 & $3.032,64$ & 34,41 & 199,05 \\
Parit Wan Salim & 978,91 & $2.746,86$ & 39,33 & 165,72 \\
Parit Makmur & 763,68 & $2.592,72$ & 37,47 & 107,91 \\
Sungai Putat & 635,25 & $8.606,16$ & 154,48 & 328,45 \\
Sungai Selamat & 553,03 & $4.167,31$ & 179,63 & 371,55 \\
\hline \multicolumn{1}{|c|}{ Total } & $\mathbf{3 . 5 6 3 , 0 5}$ & $\mathbf{2 1 . 1 4 5 , 6 9}$ & $\mathbf{4 4 5 , 3 2}$ & $\mathbf{1 . 1 7 2 , 6 9}$ \\
\hline \multicolumn{1}{|c|}{ Total } & $\mathbf{3 . 5 6 3}$ & $\mathbf{2 1 . 1 4 6}$ & $\mathbf{4 4 5}$ & $\mathbf{1 . 1 7 3}$ \\
\hline
\end{tabular}


Besar beban pencemaran dari masing-masing anak sungai/parit akan ditampilkan didalam bentuk grafik sesuai dengan parameter-parameter yang dianalisis.

1. Biological Oxygen Demand (BOD)

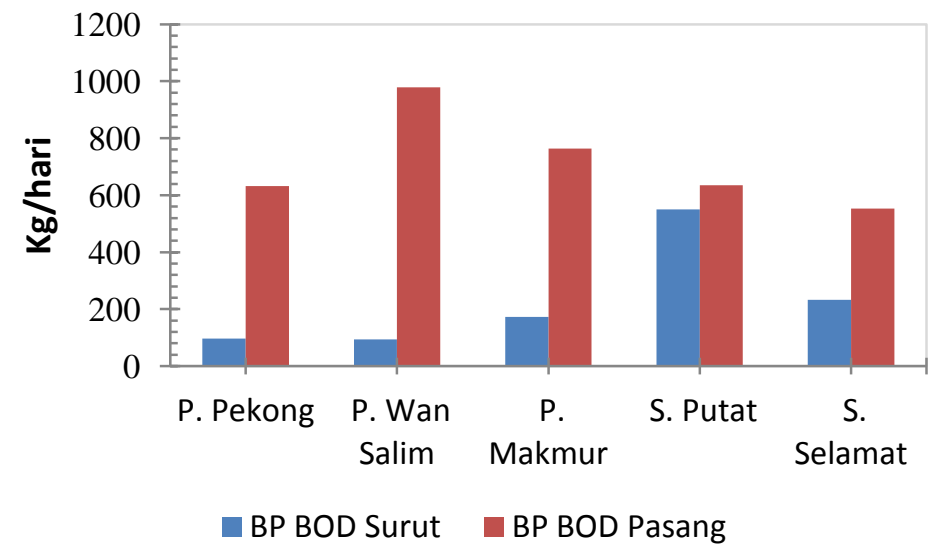

Gambar 1. Beban Pencemaran BOD pada Keadaan Pasang dan Surut

Beban Pencemaran BOD yang tertinggi pada kondisi pasang terletak di Parit Wan Salim sebesar $978,91 \mathrm{~kg}$ hari dan beban pencemaran BOD pada kondisi surut yang tertinggi terletak di Sungai Putat sebesar 549,42 kg/hari.

2. Chemical Oxygen Demand (COD)

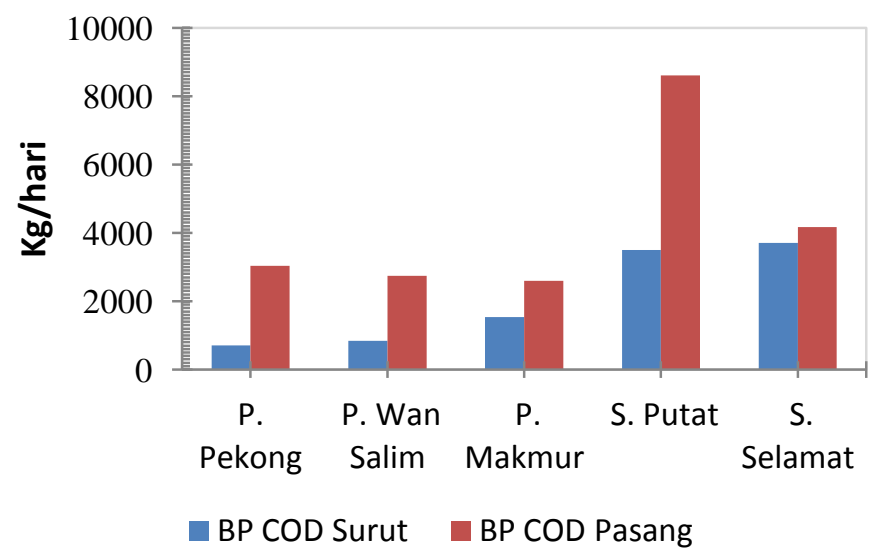

Gambar 2. Beban Pencemaran COD pada Keadaan Pasang dan Surut

Beban Pencemaran COD yang tertinggi pada kondisi pasang terletak di Sungai Putat sebesar $8.606,16 \mathrm{~kg} / \mathrm{hari}$ dan beban pencemaran COD pada kondisi surut yang tertinggi terletak di Sungai Selamat sebesar 3.711,95 kg/hari. 
3. Total Fosfat

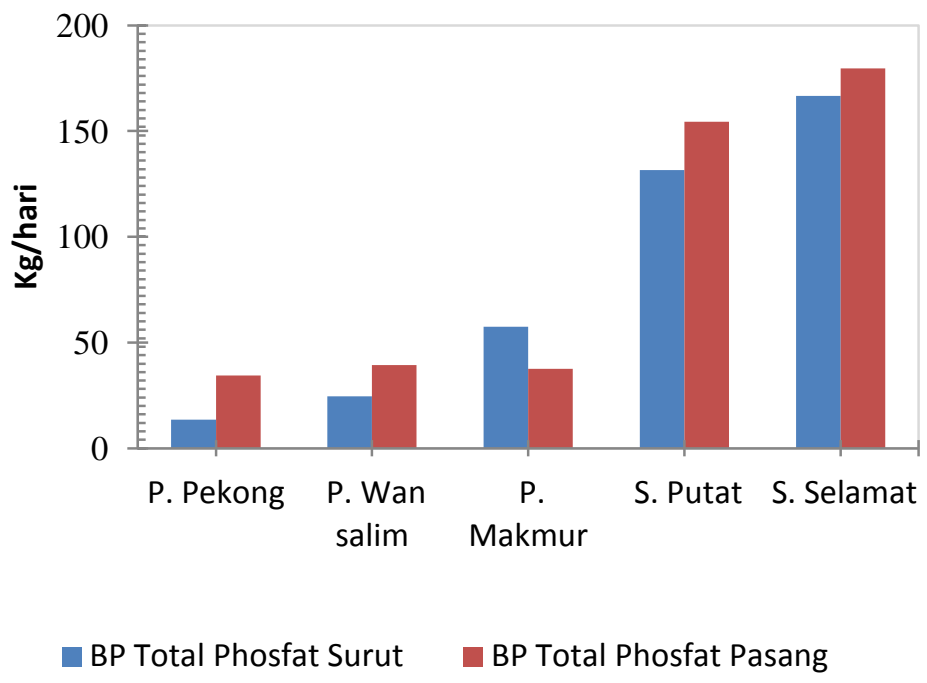

Gambar 3. Beban Pencemaran Total Fosfat pada Keadaan Pasang dan Surut

Beban Pencemaran Total Fosfat yang tertinggi pada kondisi pasang terletak di Sungai Selamat sebesar $179,63 \mathrm{~kg} /$ hari dan beban pencemaran Total Fosfat pada kondisi surut yang tertinggi terletak di Sungai Selamat pula sebesar $166,59 \mathrm{~kg} / \mathrm{hari}$.

4. Total Nitrogen

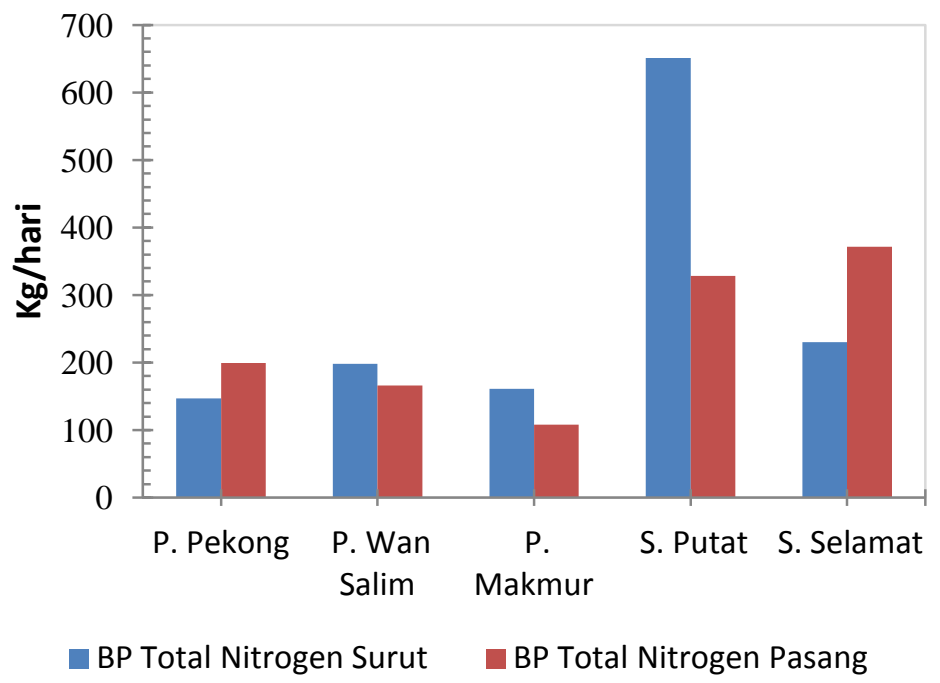

Gambar 4. Beban Pencemaran Total Nitrogen pada Keadaan Pasang dan Surut

Beban Pencemaran Total Nitrogen yang tertinggi pada kondisi pasang terletak di Sungai Selamat sebesar $371,55 \mathrm{~kg} /$ hari dan beban pencemaran Total Fosfat pada kondisi surut yang tertinggi terletak di Sungai Putat sebesar $651,10 \mathrm{~kg} / \mathrm{hari}$.

Total beban pencemaran yang masuk ke Sungai Kapuas dapat dilihat pada Tabel 9. 
Tabel 9. Total Beban Pencemaran yang Masuk ke Sungai Kapuas

\begin{tabular}{|c|c|c|c|c|}
\hline \multirow{2}{*}{ Kondisi Aliran } & \multicolumn{4}{|c|}{ Total Beban Pencemaran (kg/hari) } \\
\cline { 2 - 5 } & BOD & COD & Total Fosfat & Total Nitrogen \\
\hline Surut & 1.146 & 10.301 & 394 & 1.387 \\
Pasang & 3.563 & 21.146 & 445 & 1.173 \\
\hline
\end{tabular}

Pada Tabel 9 dapat dilihat nilai yang besar ini menguatkan bahwa Sungai Kapuas dapat dikatakan sudah tercemar. Pernyataan ini sesuai dengan Pusat Pengelolaan Ekoregion Kalimantan Kementerian Lingkungan Hidup yang melakukan perhitungan daya tampung beban pencemaran Sungai Kapuas di Kalbar. Hasilnya menunjukkan adanya pencemaran dan melampaui kelas yang ada.

\section{G. Estimasi Potensi Beban Pencemaran Domestik}

Perkiraan beban pencemaran oleh air limbah domestik atau disebut dengan potensi beban pencemaran dapat dilakukan berdasarkan metode estimasi. Proyeksi jumlah penduduk disetiap tahun perlu dilakukan perhitungan karena dalam menghitung potensi beban pencemaran ini diperlukannya data jumlah penduduk dan kepadatan penduduk yang tinggal disekitar lokasi DTH yang dihitung buangan dari limbah domestiknya.

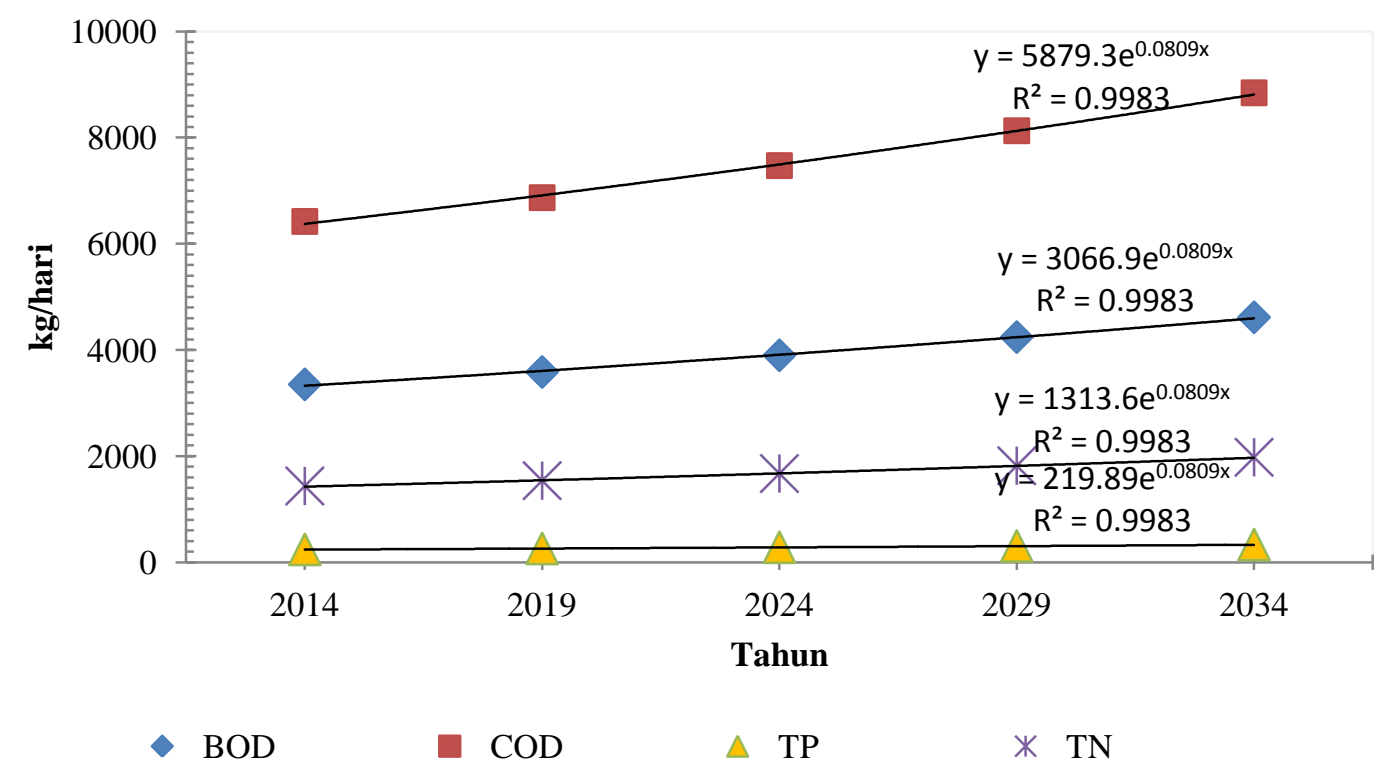

Gambar 5. Grafik Total Potensi Beban Pencemaran pada enam anak sungai/parit untuk tahun 2014-2034

4. Kesimpulan

Berdasarkan hasil penelitian dan pembahasan dapat ditarik kesimpulan sebagai berikut:

1. Nilai total beban pencemaran dari lima anak sungai/parit adalah sebagai berikut :

- Kondisi Surut : $B O D=1.146 \mathrm{~kg} / \mathrm{hari}, \mathrm{COD}=10.301 \mathrm{~kg} /$ hari, Total Phosfat $=394 \mathrm{~kg} / \mathrm{hari}$ dan Total Nitrogen $=1.387 \mathrm{~kg} /$ hari. 
- $\quad$ Kondisi Pasang : BOD $=3.563 \mathrm{~kg} / \mathrm{hari}, \mathrm{COD}=21.146 \mathrm{~kg} / \mathrm{hari}$, Total Phosfat $=445 \mathrm{~kg} / \mathrm{hari}$ dan Total Nitrogen $=1.173 \mathrm{~kg} /$ hari.

2. Potensi beban pencemaran (PBP) dihitung sampai 20 tahun kedepan. potensi beban pencemaran yang dihasilkan dari kegiatan domestik yaitu pemukiman yang berada disekitar anak sungai / parit setiap dalam lima tahun akan naik sebesar $8 \%$. PBP dari setiap parameter sebagai berikut : BOD $=4.612 \mathrm{~kg} / \mathrm{hari}$, COD $=8.841 \mathrm{~kg} /$ hari, Total Nitrogen $=1.975 \mathrm{~kg} /$ hari dan Total Phosfat $=331 \mathrm{~kg} / \mathrm{hari}$.

3. Upaya pengendalian pencemaran air yang bisa dilakukan di Kota Pontianak adalah:

a) Diharapkan pembinaan kesadaran masyarakat seperti adanya pendidikan dari usia dini khususnya yang tinggal di sekitar anak sungai/ parit agar tidak membuang sampah langsung ke anak sungai/parit

b) Merealisasikan pembangunan rencana pembuatan IPAL (Instalasi Pengolahan Air Limbah) di Kota Pontianak.

c) Pada industri besar yang sudah mempunyai IPAL (Instalasi Pengolahan Air Limbah) diharapkan dapat merawat IPAL tersebut sehingga tidak menghasilkan limbah yang melampaui baku mutu.

\section{Ucapan Terima Kasih}

Penulis mengucapkan terima kasih kepada Allah SWT serta kedua orang tua yang telah memberikan dukungan secara moril dan materil. Terima kasih juga kepada Bapak Dr. Ir. Johnny MTS, M.Sc dan Ibu Rizki Purnaini ST, MT selaku dosen pembimbing dalam penelitian ini serta teman-teman Teknik Lingkungan 2010 yang banyak membantu dalam penyelesaian skripsi ini, dan tak lupa pula kepada teman-teman angkatan 2010 Fakultas Teknik UNTAN.

\section{Referensi}

Badan Pusat Statistik Kota Pontianak. 2013. Pontianak dalam Angka 2012. Pontianak: BPS Kota Pontianak

Effendi, H. 2003. Telaah Kualitas Air Bagi Pengelolaan Sumber Daya Alam dan

Lingkungan Perairan. Penerbit Kanisius. Yogyakarta. 